\title{
Persepsi Mahasiswa Atas Kualitas Pelayanan Laboratorium Bank Mini STIE Kesatuan dan Implikasinya Terhadap Kepuasan Mahasiswa
}

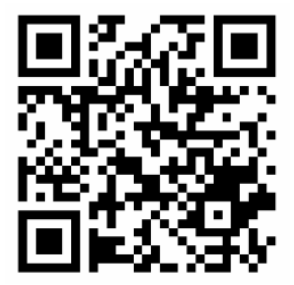

\author{
Muhammad Ariffin ${ }^{1}$ Suharmiati² Andi Yudha Amwila ${ }^{3}$
}

\begin{abstract}
Abstrak
Tujuan Penelitian ini adalah untuk mengukur pengaruh kualitas pelayanan Laboratorium Bank Mini dengan dimensi buktifisik, kehandalan, ketanggapan, jaminan, dan empati terhadap kepuasan mahasiswa STIE Kesatuan Bogor. Penelitian dilaksanakan di STIE Kesatuan Bogor dengan responden sebanyak 100 orang mahasiswa. Metode partial least square digunakan untuk menganalisis data. Hasil penelitian menunjukkan bahwa Bukti Fisik, Kehandalan, Ketanggapan, Jaminan dan Empati memiliki pengaruh yang positif dan nyata terhadap kepuasan mahasiswa pengguna Laboratorium Bank Mini STIE Kesatuan.
\end{abstract}

Kata Kunci: Kualitas Pelayanan, Kepuasan, Laboratorium Bank Mini

\section{Abstract}

The Purpose of this research is to measure the influence of the service quality of Laboratorium Bank Mini on student's satisfaction. This research was conducted in STIE Kesatuan Bogor with 100 respondents. Data were analyzed using partial least square method. The results showed that the Physical Evidence, Reliability, Responsiveness, Assurance and Empathy has a significant and positive influence on the student satisfaction of Laboratorium Bank Mini STIE Kesatuan.

Keywords: Service Quality, Student Satisfaction, Laboratorium Bank Mini.

\section{Pendahuluan}

Laboratorium Bank Mini sebagai bagian kelengkapan dari proses pembelajaran yang dilakukan di Perguruan Tinggi memiliki peran penting untuk menghasilkan SDM yang handal. Laboratorium Bank Mini sejatinya merupakan sentra layanan secara khusus bagi mahasiswa yang menempuh mata kuliah Praktikum Bank Mini atau yang sejalur dengannya.
1. Program Studi Keuangan dan Perbankan, Sekolah Tinggi IImu Ekonomi Kesatuan, Jalan

Ranggagading No. 1 Bogor Indonesia

2. Program Studi Keuangan dan Perbankan, Sekolah Tinggi Ilmu Ekonomi Kesatuan, Jalan Ranggagading No. 1 Bogor Indonesia

3. Program Studi Manajemen, Sekolah Tinggi IImu Ekonomi Kesatuan, Jalan

Ranggagading No. 1 Bogor Indonesia

EMail

haji.mariffin@gmail.com

Submitted Februari 2018

Accepted : Juni 2018
JAS-PT

RNAL ANALISIS SISTEM PENDIDIKAN TINGGI ISSN $2580-5339$ eISSN $2620-5718$

Volume 2

Nomor 1

JULI 2018

Hal $13-18$ 
Peningkatan pelayanan laboratorium Bank Mini menjadi keniscayaan untuk dilakukan guna memenuhi kebutuhan dan kepuasan mahasiswa sebagai pengguna serta menunjang keberhasilan mahasiswa dalam proses pembelajaran. Mahasiswa yang memasuki dan menggunakan fasilitas Laboratorium Bank Mini tentu tidak sebatas penggunaan dimaksud, akan tetapi di dalam prosesnya dibutuhkan pelayanan optimal dari petugas atau pengelola Laboratorium Bank Mini sehingga berimplikasi terhadap keberhasilan proses pembelajarannya.

Untuk mengetahui faktor-faktor yang membentuk kualitas pelayanan dan implikasinya terhadap kepuasan mahasiswa, peneliti mencoba melihat pengaruh tersebut berdasarkan pada lima dimensi, yaitu: Bukti fisik, Kehandalan, Ketanggapan, Jaminan, dan Empati.

Berdasarkan latar belakang di atas dirumuskan masalah sebagai berikut: Sejauhmana pengaruh kualitas pelayanan Laboratorium Bank Mini yang terdiri dari; buktifisik, kehandalan, ketanggapan, jaminan, dan empati terhadap kepuasan mahasiswa STIE Kesatuan Bogor

\section{Tinjauan Pustaka}

\section{Hubungan Kualitas Pelayanan dengan Kepuasan}

Lima faktor utama dari kualitas pelayanan yang harus diperhatikan olehperusahaan untuk mengetahui tingkat kepuasan pelanggan, menurut Parasuraman etal. (1988) yaitu "Tangible, reliability, responsivness, assurance, and empathy".Kualitas pelayanan, terutama untuk industri jasa. Pelanggan akan merasa puas bilamereka mendapatkan pelayanan yang baik atau yang sesuai dengan yang diharapkan.

Pencapaian kepuasan pelanggan melalui kualitas pelayanan, dapat ditingkatkandengan beberapa pendekatan sebagai berikut Kotler (dalam Lupiyoadi, 2001), yaitu :

a. Memperkecil kesenjangan-kesenjangan yang terjadi antara pihak manajemendan pelanggan.

b. Perusahaan harus mampu membangun komitmen bersama untuk menciptakanvisi di dalam perbaikan proses pelayanan.

c. Memberi kesempatan pada pelanggan untuk menyampaikan keluhan.

d. Mengembangkan dan menerapkan accountable, proactive, dan patnership marketing sesuai dengan situasi pemasaran

\section{Metodologi Penelitian}

Penelitian ini dilaksanakan di Laboratorium Bank Mini STIE Kesatuan di Jalan Ranggagading No. 1 Bogor, selama empat bulan mulai Maret 2017. Laboratorium Bank Mini STIE Kesatuan merupakan salah satu unit pelaksana teknis dari institusi STIE Kesatuan yang menjalankan fungsi layanan praktikum Bank Mini kepada para sivitas akademika STIE Kesatuan. Pendekatan dalam penelitian ini adalah studi kasus.

JAS-PT

ISSN $2580-5339$ elSSN $2620-5718$ Volume 2

Nomor 1

JULI 2018

Hal $13-18$ Populasi dari penelitian ini adalah mahasiswa STIE Kesatuan dengan sampel sebanyak 100 orang mahasiswa yang telah memanfaatkan fasilitas Laboratorium Bank Mini dalam proses pembelajaran atau perkuliahan.

Metode Pengumpulan Data Penelitian ini melalui wawancara, survey menggunakan kuesioner dan Studi dokumentasi data sekunder. Operasional Variabel Penelitian ini sebagaimana Tabel 1. 
Berdasarkan tujuan penelitian, perumusan masalah dan kerangka pemikiran, peneliti memberikan hipotesis adalah sebagai berikut : Kualitas pelayanan yang terdiri dari; bukti fisik, kehandalan, ketanggapan, jaminan dan empati, berpengaruh terhadap kepuasan mahasiswa STIE Kesatuan Bogor

Tabel 1. Definisi Operasional Variabel Penelitian Pelayanan Laboratorium Bank Mini

\begin{tabular}{|c|c|c|c|}
\hline Variabel & Definisi & Indikator & $\begin{array}{c}\text { Skala } \\
\text { Pengukuran }\end{array}$ \\
\hline Bukti Fisik (X1) & $\begin{array}{l}\text { Aspek-aspek } \\
\text { nyata yang dapat } \\
\text { dilihat pada } \\
\text { Laboratorium } \\
\text { Bank Mini }\end{array}$ & $\begin{array}{l}\text { 1. Fasilitas Lab Bank Mini lengkap } \\
\text { 2. Lab Bank Mini bersih, indah, nyaman dan rapi } \\
\text { 3. Petugas Lab Bank Mini berpenampilan bersih } \\
\text { dan rapi } \\
\text { 4. Fasilitas Lab Bank Mini bersih, nyaman dan } \\
\text { rapi }\end{array}$ & Likert \\
\hline Kehandalan (X2) & $\begin{array}{l}\text { Aspek-aspek } \\
\text { kehandalan } \\
\text { sistem pelayanan } \\
\text { yang diberikan } \\
\text { oleh Lab Bank } \\
\text { Mini }\end{array}$ & $\begin{array}{l}\text { 1. Kesesuaian dan Ketepatan Waktu Pelayanan } \\
\text { dengan jadwal yang telah tersusun } \\
\text { 2. Perhatian serius Lab Bank Mini terhadap } \\
\text { mahasiswa yang menghadapi masalah } \\
\text { 3. Kehandalan Lab Bank Mini dalam } \\
\text { penyampaina pelayanan dari awal sampai } \\
\text { akhir } \\
\text { 4. Keakuratan dalam pengadministrasian dan } \\
\text { pendokumentasian }\end{array}$ & Likert \\
\hline Ketanggapan (X3) & $\begin{array}{l}\text { Keinginan untuk } \\
\text { membantu } \\
\text { mahasiswan dan } \\
\text { menyediakan jasa } \\
\text { dan pelayanan } \\
\text { yang dibutuhkan }\end{array}$ & $\begin{array}{l}\text { 1. Petugas Lab Bank Mini tanggap dalam } \\
\text { merespon keluhan dan permintaan } \\
\text { mahasiswa } \\
\text { 2. Kesediaan petugas Lab Bank Mini dalam } \\
\text { membantu kesulitan yang dihadapi } \\
\text { mahasiswa } \\
\text { 3. Keluangan waktu petugas Lab Bank Mini } \\
\text { menanggapi permintaan mahasiswa } \\
\text { 4. Petugas Lab Bank Mini profesional dalam } \\
\text { melayani mahasiswa saat jam sibuk }\end{array}$ & Likert \\
\hline Jaminan (X4) & $\begin{array}{l}\text { Adanya jaminan } \\
\text { yang diberikan } \\
\text { berupa } \\
\text { kenyamanan, } \\
\text { kompetensi } \\
\text { sumber daya } \\
\text { dalam pelayanan }\end{array}$ & $\begin{array}{l}\text { 1. Kompetensi petugas Lab Bank Mini dalam } \\
\text { pelayanan } \\
\text { 2. Mahasiswa merasa nyaman selama } \\
\text { berkomunikasi dan berhubungan dengan } \\
\text { petugas Lab Bank Mini } \\
\text { 3. Petugas Lab Bank Mini memiliki kesabaran } \\
\text { saat pelayanan } \\
\text { 4. Kekeliruan dan kesalahan yabng terjadi } \\
\text { segera diperbaiki }\end{array}$ & Likert \\
\hline Empati (X5) & $\begin{array}{l}\text { Kemudahan } \\
\text { dalam } \\
\text { mendapatkan } \\
\text { pelauanan, } \\
\text { keramahaman, } \\
\text { komunikasi dan } \\
\text { memahami } \\
\text { kebutuhan } \\
\text { konsumen } \\
\end{array}$ & $\begin{array}{l}\text { 1. Petugas Lab Bank Mini mudah dalam } \\
\text { memberikan pelayanan } \\
\text { 2. Petugas Lab Bank Mini ramah dalam } \\
\text { berkomunikasi melayani mahasiswa } \\
\text { 3. Perhatian petugas Lab Bank Mini secara } \\
\text { individu kepada mahasiswa } \\
\text { 4. Petugas Lab Bank Mini paham akan } \\
\text { kebutuhan dan perasaan mahasiswa }\end{array}$ & Likert \\
\hline $\begin{array}{l}\text { Kepuasan } \\
\text { Mahasiswa }\end{array}$ & $\begin{array}{l}\text { Kepuasan dimana } \\
\text { Keinginan, } \\
\text { harapan dan } \\
\text { kebutuhan dapat } \\
\text { terpenuhi }\end{array}$ & $\begin{array}{l}\text { 1. Perasaan Puas terhadap kinerja Lab Bank } \\
\text { Mini } \\
\text { 2. Kesesuaian Pelayanan Lab Bank Mini } \\
\text { dengan harapan mahasiswa } \\
\text { 3. Kualitas keseluruhan pelayanan yang } \\
\text { diberikan Lab Bank Mini }\end{array}$ & Likert \\
\hline
\end{tabular}

Sumber : Data Sekunder diolah, 2017

JAS-PT

JURNAL ANALISIS SISTEM PENDIDIKAN TINGG ISSN $2580-5339$ eISSN $2620-5718$

Volume 2

Nomor 1

JULI 2018

Hal $13-18$

FORUM DOSEN INDONESIA

Responden penelitian ini didominasi oleh responden berjenis kelamin wanita. Dari aspek usia, dominan adalah responden berusia 20 tahun. Responden berasal dari 
empat program studi yang diselenggarakan STIE Kesatuan. Mayoritas responden adalah mahasiswa kelas reguler pagi.

Tabel 1 Distribusi Frekuensi Responden Berdasarkan Karakteristik

\begin{tabular}{lcc}
\hline \multicolumn{1}{c}{ Karakteristik } & Prosentase & Jumlah \\
\hline Jenis Kelamin Responden & & \\
Laki-laki & 30,0 & 100 \\
Wanita & 70,0 & \\
Usia Responden & 10,0 & \\
19 Tahun & 35,0 & 100 \\
20 Tahun & 25,0 & \\
21 Tahun & 23,0 & \\
22 Tahun & 4,0 & \\
23 Tahun & 3,0 & 100 \\
> 23 Tahun & & \\
Program Studi Responden & 30,0 & \\
Manajemen S1 & 20,0 & 100 \\
Akuntansi S1 & 30,0 & \\
Keuangan dan Perbankan D3 & 20,0 & \\
Akuntansi D3 & & \\
Kelas Perkuliahan Responden & 60,0 & \\
Kelas Reguler Pagi & 20,0 & \\
Kelas Reguler Sore & 20,0 & \\
Kelas Karyawan &
\end{tabular}

Sumber : Hasil Pengolahan Data Primer, 2017

Tabel 2. Persepsi Mahasiswa atas Kualitas Pelayanan Lab. Bank Mini STIE Kesatuan

\begin{tabular}{|c|c|c|c|c|c|c|c|}
\hline \multirow{2}{*}{ Indikator } & \multicolumn{5}{|c|}{ Jawaban } & \multirow{2}{*}{$\begin{array}{c}\text { Skor } \\
\text { Skala Likert }\end{array}$} & \multirow{2}{*}{$\begin{array}{c}\text { Kriteria / } \\
\text { Kesimpulan }\end{array}$} \\
\hline & STS & TS & $\mathrm{R}$ & $S$ & SS & & \\
\hline \multicolumn{8}{|l|}{ BUKTI FISIK } \\
\hline Kelengkapan Fasilitas & 0 & 0 & 7 & 66 & 27 & $84 \%$ & SANGAT KUAT \\
\hline Kenyamanan Lab & 0 & 0 & 4 & 60 & 36 & $86 \%$ & SANGAT KUAT \\
\hline Penampilan Petugas & 0 & 0 & 1 & 66 & 33 & $86 \%$ & SANGAT KUAT \\
\hline Kebersihan Fasilitas & 0 & 0 & 4 & 62 & 34 & $86 \%$ & SANGAT KUAT \\
\hline \multicolumn{8}{|l|}{ KEHANDALAN } \\
\hline Ketepatan Pelayanan & 0 & 0 & 4 & 72 & 24 & $84 \%$ & SANGAT KUAT \\
\hline Perhatian Terhadap Mahasiswa & 0 & 0 & 5 & 65 & 30 & $85 \%$ & SANGAT KUAT \\
\hline Penyampaian Layanan & 0 & 0 & 10 & 64 & 26 & $83 \%$ & SANGAT KUAT \\
\hline Keakuratan Administrasi & 0 & 0 & 6 & 72 & 22 & $83 \%$ & SANGAT KUAT \\
\hline \multicolumn{8}{|l|}{ KETANGGAPAN } \\
\hline Respon Terhadap Keluhan & 0 & 0 & 1 & 78 & 21 & $84 \%$ & SANGAT KUAT \\
\hline Kesediaan Membantu & 0 & 0 & 1 & 77 & 22 & $84 \%$ & SANGAT KUAT \\
\hline Keluangan Waktu & 0 & 0 & 7 & 73 & 20 & $83 \%$ & SANGAT KUAT \\
\hline Profesionalitas Pelayanan & 0 & 0 & 13 & 69 & 18 & $81 \%$ & SANGAT KUAT \\
\hline \multicolumn{8}{|l|}{ JAMINAN } \\
\hline Kompetensi Petugas & 0 & 0 & 4 & 80 & 16 & $82 \%$ & SANGAT KUAT \\
\hline Komunikasi Petugas & 0 & 0 & 2 & 73 & 25 & $85 \%$ & SANGAT KUAT \\
\hline Kesabaran Petugas & 0 & 0 & 4 & 71 & 25 & $84 \%$ & SANGAT KUAT \\
\hline Perbaikan Kekeliruan & 0 & 0 & 3 & 74 & 23 & $84 \%$ & SANGAT KUAT \\
\hline \multicolumn{8}{|l|}{ JAMINAN } \\
\hline Kemudahan Pelayanan & 0 & 0 & 1 & 79 & 20 & $84 \%$ & SANGAT KUAT \\
\hline Keramahan Pelayanan & 0 & 0 & 0 & 83 & 17 & $83 \%$ & SANGAT KUAT \\
\hline Perhatian secara Individu & 0 & 0 & 7 & 85 & 8 & $80 \%$ & SANGAT KUAT \\
\hline Paham Perasaan Mahasiswa & 0 & 0 & 7 & 84 & 9 & $80 \%$ & SANGAT KUAT \\
\hline \multicolumn{8}{|l|}{ KEPUASAN } \\
\hline Kepuasan Atas Layanan & 0 & 0 & 0 & 38 & 62 & $92 \%$ & SANGAT KUAT \\
\hline Kesesuaian Harapan dgn Kenyataan & 0 & 0 & 0 & 42 & 58 & $92 \%$ & SANGAT KUAT \\
\hline Kualitas Keseluruhan & 0 & 0 & 0 & 35 & 65 & $93 \%$ & SANGAT KUAT \\
\hline
\end{tabular}

FORUM DOSEN INDONESIA

Sumber: Data Primer Diolah 


\section{Persepsi Responden Atas Kualitas Pelayanan}

Berdasarkan Tabel 2 dan Tabel 3, dapat diketahui bahwa seluruh indikator kualitas pelayanan dan kepuasan mahasiswa dipersepsikan sangat kuat oleh seluruh responden. Hal ini menunjukkan bahwa secara keseluruhan mahasiswa yang menjadi responden penelitian ini bersepakat bahwa pelayanan Laboratorium Bank Mini STIE Kesatuan telah memiliki kualitas yang sangat bagus. Demikian pula dengan tingkat kepuasan mahasiswa relatif sangat puas dalam menerima layanan Laboratorium Bank Mini STIE Kesatuan.

Tabel 3. Kategorisasi Interpretasi Skor

\begin{tabular}{cc}
\hline Nilai Skor & Kriteria Interpretasi Skor \\
\hline Angka $0 \%-20 \%$ & Sangat Lemah \\
Angka $21 \%-40 \%$ & Lemah \\
Angka $41 \%-60 \%$ & Cukup \\
Angka $61 \%-80 \%$ & Kuat \\
Angka $81 \%-100 \%$ & Sangat Kuat
\end{tabular}

Untuk mengetahui lebih lanjut tentang pengaruh variabel-variabel kualitas pelayanan terhadap kepuasan mahasiswa dilakukan analisis data menggunakan metode partial least square.

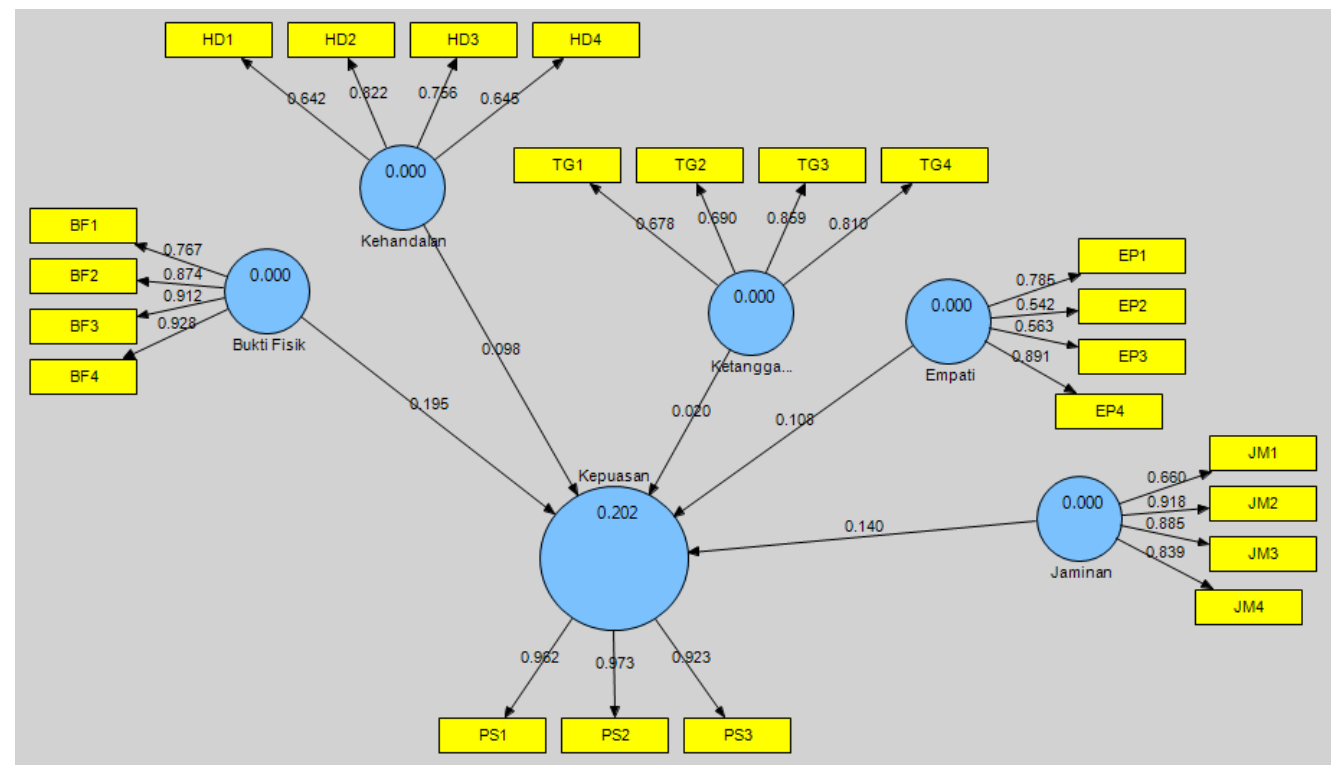

Gambar 1 Model Kualitas Pelayanan Laboratorium Bank Mini

Tabel 4 Nilai Koefisien dan T-Hitung Pengaruh Variabel Kualitas Pelayanan terhadap Kepuasan Mahasiswa Laboratorium Bank Mini STIE Kesatuan

\begin{tabular}{lccccc}
\hline \multicolumn{1}{c}{ Variabel } & $\begin{array}{c}\text { Original } \\
\text { Sample (O) }\end{array}$ & $\begin{array}{c}\text { Sample } \\
\text { Mean }(\mathrm{M})\end{array}$ & $\begin{array}{c}\text { Standard } \\
\text { Deviation (STDEV) }\end{array}$ & $\begin{array}{c}\text { Standard Error } \\
(\text { STERR) }\end{array}$ & $\begin{array}{c}\text { T Statistics } \\
(\text { (O/STERR|) }\end{array}$ \\
\hline Bukti Fisik $\rightarrow$ Kepuasan & 0.194538 & 0.183896 & 0.130885 & 0.130885 & 2.486334 \\
Empati $\rightarrow$ Kepuasan & 0.107917 & 0.139627 & 0.147618 & 0.147618 & 2.731060 \\
Jaminan $\rightarrow$ Kepuasan & 0.140188 & 0.124724 & 0.144785 & 0.144785 & 1.968248 \\
Kehandalan $>>$ Kepuasan & 0.097825 & 0.120617 & 0.126753 & 0.126753 & 2.771776 \\
Ketanggapan $\rightarrow$ Kepuasan & 0.020425 & 0.025472 & 0.163434 & 0.163434 & 2.124973 \\
\hline
\end{tabular}

\section{Sumber: Data Primer Diolah, 2017}

Merujuk kepada Gambar 1, seluruh indikator Kualitas Pelayanan dan Kepuasan Mahasiswa telah memenuhi convergenty validity, discriminant validity dan reliability yang baik, sehingga tidak ada satu pun indikator yang dikeluarkan dari model. Hal ini dapat terlihat dari nilai loading factor masing-masing indikator yang melebihi 0,500 .

JAS-PT

JURNAL ANALISIS SISTEM PENDIDIKAN TINGGI ISSN $2580-5339$ eISSN $2620-5718$

Volume 2

Nomor 1

JULI 2018

Hal $13-18$

FORUM DOSEN INDONESIA 
Tabel 4 menampilkan nilai koefisien yang positif dari setiap variabel, hal ini menunjukkan bahwa seluruh variabel kualitas pelayanan yang terdiri dari Bukti Fisik, Empati, Jaminan, Kehandalan dan Ketanggapan memiliki pengaruh yang positif terhadap kepuasan mahasiswa. Pengaruh tersebut bersifat nyata atau signifikan. Terbukti dengan nilai signifikansi dari masing-masing variabel yang melebihi 1,96 (Bukti Fisik 2,48; Empati 2,73; Jaminan 1,97; Kehandalan 2,77 dan Ketanggapan 2,12).

Seluruh responden penelitian ini telah bersepakat untuk menyatakan bahwa kualitas pelayanan petugas serta fasilitas Laboratorium Bank Mini STIE Kesatuan telah memuaskan dan membuat nyaman para mahasiswa dalam proses pembelajaran.

\section{Penutup}

\section{Simpulan}

Kesimpulan penelitian ini adalah:

a. Keseluruhan mahasiswa yang menjadi responden penelitian ini bersepakat bahwa pelayanan Laboratorium Bank Mini STIE Kesatuan telah memiliki kualitas yang sangat bagus.

b. Tingkat kepuasan mahasiswa relatif sangat puas dalam menerima layanan Laboratorium Bank Mini STIE Kesatuan.

c. Bukti Fisik, Kehandalan, Ketanggapan, Empati, dan Jaminan memiliki pengaruh yang positif dan nyata terhadap Kepuasan Mahasiswa.

\section{Implikasi Manajerial}

Rekomendasi yang dapat diajukan antara lain :

a. Mempertahankan kualitas pelayanan untuk senantiasa memuaskan mahasiswa menjadi keniscayaan untuk mendapat perhatian penuh dari manajemen STIE Kesatuan.

b. Untuk penelitian selanjutnya, dapat dimasukkan variabel lainnya yang relevan, untuk memastikan secara optimal tingkat kepuasan mahasiswa dalam menggunakan fasilitas Laboratorium Bank Mini.

\section{Daftar Pustaka}

Ariani, Dorothea Wahyu. 2003. Manajemen Kualitas Pendekatan Sisi Kualitatif. Yogyakarta: Ghalia Indonesia

Ellitan, Lenna. 2001. "Strategi Mendongkrak Kualitas Pelayanan". Jurnal Ekonomi Sekolah Tinggi Ilmu Ekonomi Indonesia 15/Th. X.

Kotler, Philip and Alan R. Andreason. 1995. Strategi Pemasaran untuk Organisasi Nirlaba. Edisi Ketiga. Penerjemah Ova Emi Emiliam. Penyunting Mubasyir Hasan Basri. Gadjah Mada University, Yogyakarta.

Mardalis, Ahmad. 2005. "Meraih Loyalitas Pelanggan". Jurnal Manajemen dan Bisnis 9 No. 2 (Tahun 2005) : 111-119.

Mulyana, M., 2012. Consumer Behaviour: Sukses Dengan Memahami Konsumen. ISBN 978-979-18531-6-3, Bogor: Kesatuan Press.

JAS-PT

ISSN $2580-5339$ elSSN $2620-5718$

Volume 2

Nomor 1

JULI 2018

Hal $13-18$

FORUM DOSEN INDONESIA
Nurendah, Y. and Mulyana, M., 2013. Analisis Pengaruh Kualitas Pelayanan Perpustakaan Terhadap Kepuasan dan Hubungannya dengan Loyalitas Mahasiswa. Jurnal IImiah Manajemen Kesatuan, 1(1), pp.91-105.

Parasuraman, A. Zeithaml V.A. and Berry L.L. 1988. "A Multiple Item Scale for Measuring Consumer Perception of Service Quality". Journal of Retailling Vol. 64, spring: $12-14$.

Siamat, Dahlan. 2001. Manajemen Bank Umum. Jakarta: LPFEUI

Undang-Undang Np.10. 1998 tentang Perbankan 